\title{
A EXPERIÊNCIA PERCEPTIVA É O SOLO DO CONHECIMENTO DE PESSOAS COM E SEM DEFICIÊNCIAS SENSORIAIS
}

\author{
Elcie F. Salzano Masini
}

\begin{abstract}
RESUMO. Este artigo diz respeito aos caminhos de pessoas, na ausência de um dos sentidos de distância - visão ou audição - obterem informações sobre o que as cerca e elaborarem esses dados, organizando e compreendendo o que está a seu redor. Fundamenta-se em Merleau-Ponty, na ênfase dada por esse autor à experiência corporal e à consciência corporal do mundo sensível.
\end{abstract}

Palavras-chave: deficiências sensoriais; experiência perceptiva; consciência corporal.

\section{THE PERCEPTUAL EXPERIENCE IS THE BASE OF KNOWLEDGE FOR PEOPLE WITH AND WITHOUT SENSORIAL IMPAIRMENT}

\begin{abstract}
This article is regarding the ways people without one of the distant senses (vision or hearing) receive, organize and understand information about the world that is surrounding them. The approach is based upon Merleau-Ponty with the emphasis given by this author to the corporal experiences and awareness of the body to the sensible world.
\end{abstract}

Key words: sensorial deficiencies, perceptual experiences, body awareness.

\section{INTRODUÇÃO}

Esta comunicação levanta algumas questões referentes à percepção da pessoa que não dispõe dos denominados sentidos de distância, isto é, visão e audição. É uma tentativa de refletir sobre sua maneira de estar no mundo, seus significados e suas manifestações: a expressão de sua vida interior, sentimentos e impulsos emotivos; o seu perceber e o uso dos sentidos de que dispõe, bem como suas relações com pessoas e objetos no mundo onde habita.

O contato com o cotidiano de pessoas que exploram e conhecem o ambiente que as cerca, sem a visão, sem a audição, ou sem ambas, convida à reflexão. Desperta naquele que dispõe da audição e da visão interrogações sobre as formas de existência daqueles que utilizam caminhos perceptuais diferentes dos que lhe são habituais. Instiga perguntas sobre diferentes maneiras de o ser humano perceber e conhecer o mundo ao seu redor. Faz refletir sobre suas experiências perceptivas, levantando questões a respeito, como as que seguem. $\mathrm{O}$ que caracteriza a deficiência sensorial? Pode-se falar em deficiência sensorial como uma área comum de estudos sobre os que não dispõem da visão, bem como sobre os que não dispõem da audição? Seria correto caracterizar, de forma bastante simplificada, ambas as ausências, a da audição e a da visão, como déficit na aquisição de informações sobre o meio ambiente? Desse modo, o que constitui ponto de semelhança entre essas duas formas de deficiência é o que as diferencia da deficiência mental, cujo déficit se localiza na capacidade de operar os dados, assim como de compreendê-los? Partindo da concepção de que a cegueira e a surdez caracterizam-se pela falta de entrada de informações para o indivíduo elaborar e compreender o mundo circundante, pode-se, então, declarar que a problemática das pessoas surdas é semelhante à das pessoas cegas? Ou não é válida essa afirmação, devido às especificidades de cada uma

Doutora em Psicologia (área Educação) pela PUCSP e Livre Docente em Educação Especial na USP. Professora da Pós graduação da Faculdade de Educação da USP e sócia fundadora do Laboratório Interunidades de Estudos sobre Deficiências (LIDE) do Instituto de Psicologia da USP. Professora do Programa de Mestrado em Distúrbios do Desenvolvimento da Universidade Presbiteriana Mackenzie.

Endereço para correspondência: Rua dos Franceses , 498- B1. F. Apto 142 - CEP 01329-010, São Paulo- SP.

Email: elcie@mackenzie.com.br 
dessas deficiências? Considerando-se separadamente a visão e a audição, pode-se dizer que há algo em comum entre as pessoas carentes de um desses sentidos, mesmo quando há entre elas grandes diferenças individuais, genéticas, sociais e/ou culturais?

Essas questões visam, apenas, assinalar a complexidade de conhecimentos requeridos para que se saiba mais sobre as possibilidades da existência humana e para compreender as especificidades perceptuais daqueles que não dispõem de todos os órgãos dos sentidos. O ponto de partida para essa compreensão é estar atento às formas próprias de a pessoa com deficiência sensorial explorar e perceber o que a cerca, de acordo com Masini (1994), que oferece dados de pesquisa sobre as maneiras de crianças com deficiência visual perceberem e de relacionarem-se com pessoas e objetos. Essa investigação assinalou que é a consideração aos caminhos perceptuais dos que não têm a visão como sentido predominante que pode apontar as condições propícias ao seu desenvolvimento, aprendizagem, integração pessoal e social e autonomia. Evidenciou que perceber, compreender e acompanhar esse ser humano com deficiência visual na sua totalidade - na maneira como age, como se expressa, como sente, como pensa - requer que se entre em contato com seu viver, em diferentes momentos e situações.

Um caminho para isso nos sugere Merleau-Ponty (1975), ao propor que a ciência retorne ao solo do mundo sensível como é na própria vida para o próprio corpo corpo sentinela silenciosa dos atos e das palavras.

\section{A EXPERIÊNCIA PERCEPTIVA E O CONHECIMENTO}

Merleau-Ponty considera o sujeito no mundo como corpo no mundo. O sujeito da percepção é o corpo e não mais a consciência concebida separadamente da experiência vivida, consciência da qual provém o conhecimento. O corpo é, então, visto como fonte de sentidos, isto é, de significação da relação do sujeito no mundo; sujeito visto na totalidade, na sua estrutura de relações com as coisas ao seu redor. Ao falar da percepção, esse filósofo chama a atenção principalmente para o fato de que o que é percebido por uma pessoa (fenômeno) acontece num campo do qual ela faz parte; a identidade do mundo percebido vai ocorrendo através das suas próprias perspectivas e vai se construindo em movimentos de retomada do passado e abertura para o futuro, sempre sendo possíveis novas perspectivas. Para compreender a percepção é necessário considerar o sujeito da percepção e saber de sua experiência perceptiva. Neste sentido, diz-se que as coisas "se pensam" em cada pessoa, porque não é um pensar intelectual, no sentido de funcionamento de um sistema, mas sim do saber de si ao saber do objeto, já que, ao entrar em contato com o objeto, o sujeito entra em contato consigo mesmo.

A coisa e o mundo são dados como partes do meu corpo, não por sua 'geometria natural', mas sim numa conexão comparável, ou mais certamente idêntica àquela que existe entre as partes do meu corpo (Merleau-Ponty, 1971, p. 212).

A característica marcante deste enfoque está na ênfase dada ao corpo. $\mathrm{O}$ esforço desse autor foi o de mostrar que a relação no mundo é corporal e sempre significativa.

Cada um de nós está cercado de objetos que têm a marca humana e que constituem os objetos culturais. $\mathrm{O}$ primeiro objeto cultural é o corpo do outro como portador de uma experiência humana, o lugar de uma certa elaboração, de um certo horizonte. Através de seu corpo vivo, que tem a mesma estrutura do meu, sei que e como o outro se serve de objetos familiares de um mesmo mundo físico e cultural do qual compartilhamos. Ao considerar o Sujeito no mundo como corpo no mundo corpo que sente, que sabe, que compreende, MerleauPonty assinala a importância da experiência perceptiva e ensina que o conhecimento emerge do saber latente que ocorre no corpo próprio ${ }^{1}$.

A experiência perceptiva (que é corporal) surge da relação dinâmica do corpo como um sistema de forças no mundo e não da associação que vem dos órgãos dos sentidos. Assim, o corpo é visto numa totalidade, na sua estrutura de relação com as coisas ao seu redor - como uma fonte de sentidos.

Merleau-Ponty, ao tomar a percepção como solo originário do conhecimento - percepção que se dá no corpo, nas relações de significação com o que se dá ao seu derredor - aponta um caminho para se saber da pessoa com deficiência. Ele se refere aos conteúdos particulares (a especificidade) e às formas de percepção (a generalidade). Os conteúdos são os dados sensoriais (visão, tato, audição) e a forma, a organização total desses dados, que é fornecida pela função simbólica². Há uma dialética entre conteúdo e

1 corpo próprio - expressão usada para referir-se à experiência corporal de cada pessoa.

2 Função simbólica, como a entende Piaget "mecanismo comum aos diferentes sistemas de representações e como mecanismo individual cuja existência prévia é necessária para 
forma: não se pode organizar nada se não houver dados, mas estes, quando fragmentados (dissociados da função simbólica), de nada adiantam.

Para compreender a pessoa com deficiência e sua maneira de se relacionar no mundo que a cerca, cumpre considerar sempre suas estruturas perceptual e cognitiva, que exprimem ao mesmo tempo generalidade e especificidade (o conteúdo, a forma e a dialética entre ambas). O ponto de partida é, pois, saber de sua experiência perceptiva.

Uma criança, por exemplo, que nunca enxergou, tem uma experiência perceptiva diferente daquela que ficou cega nos primeiros anos de vida. Da mesma forma, uma criança que desde a gestação nunca recebeu informações sonoras tem uma experiência perceptiva diferente daquela que ficou surda aos dois ou três anos. Cada uma delas foi percebendo e conhecendo o mundo através de suas experiências pelos sentidos de que dispunha. As descrições de Hellen Keller, que perdeu a visão e a audição aos 18 meses, sobre o dia-a-dia de sua vida, ilustram, nas suas experiências, suas vias perceptivas.

Distraía-me seguindo as cercas de bucho com as mãos, para colher os primeiros lírios e violetas desabrochadas que eu descobria apenas com o olfato(...). De repente, meus dedos encontravam uma planta que eu reconhecia pelas folhas e flores...percebia quando mamãe e titia iam sair, pegando nos seus vestidos(...) (...) Pela vibração a pancada da porta fechando, e por outras vibrações indeterminadas, percebia que chegara visita. (Hellen Keller, 1939, p. 14).

Os dados do tato, do olfato e da audição, que compunham a experiência perceptiva de Hellen Keller, eram organizados e iam-na ajudando a ter conhecimento do seu próprio mundo, no qual ia construindo sua identidade.

Questões que dizem respeito à experiência, à percepção e ao conhecimento do mundo, na ausência de um dos sentidos de distância, têm sido retomadas por psicólogos (Ormelezi, 2000), educadores (Salomon, 2000), neurologistas (Rodrigues, 1993), oftalmologistas (Veitzman, 2002), fonoaudiólogos (Moura,1993), e foniatras (Spinelli, 2002), em atendimentos e pesquisas. Têm eles evidenciado que a ausência, a recuperação ou a perda de um dos sentidos envolvem um conjunto de processos complexos. Como ilustração, vale retomar a concepção espacial para a pessoa cega, na qual estão envolvidos muito

tornar possíveis as interações do pensamento entre indivíduos (...) papel essencial na elaboração de conceitos" (Piaget, 1971, p. 14). mais do que fatores perceptivo-cognitivos, enquanto fisiológicos, pois dizem respeito a como a pessoa percebe e constrói seu próprio mundo, como evidenciam os dados a seguir.

De acordo com investigações de Ochaita, a concepção de espaço pelo cego é organizada por meio de referencial temporal.

Assim é possível que os que nasceram cegos cheguem a conhecer o espaço projetivo mediante consideração às relações euclidianas ou métricas e que, desse modo, sua compreensão da perspectiva seja de caráter fundamentalmente temporal, tal como afirmava Drumond em 1975 (Ochaita, 1984, p. 102).

A recuperação da visão por parte de uma pessoa adulta,exigirá mudança desse referencial temporal seqüencial para outro, visual - espacial. Isso envolve uma reorganização ampla de sua forma de estar no mundo, que é registrada, inclusive, neurologicamente, conforme afirma Sacks:

É de se suspeitar que as partes táteis e auditivas do córtex são alargadas nos cegos, e podem até se expandir para o que normalmente é o córtex visual o córtex de um adulto cego já se tornou altamente adaptado a percepções organizadas no tempo e não no espaço (Sacks, 1997, p. 153).

Essa afirmação reitera a complexidade envolvida na reorganização de uma pessoa, quando ocorre perda ou reaquisição do sentido da visão, e convida a pensar nas condições requeridas para a sua reabilitação.

Retomar as histórias de pessoas deficientes sensoriais - de sua infância, de seu aprendizado, de suas relações, de suas descobertas e de suas dificuldades - é uma forma de tomar contato e refletir sobre as condições para seu desenvolvimento e suas readaptações. Suas histórias poderão apontar outros potenciais a serem explorados, cabendo às áreas de conhecimento investigar como poderão contribuir nesse sentido. Os excertos apresentados a seguir, retirados do depoimento de Elizabeth Sá (2002), ilustram o que ficou dito.

(...) A perda cada vez mais acentuada da visão alterava a rotina da família e repercutia na escola e em outros espaços sociais. Apesar das restrições e de um percurso escolar sinuoso, eu gostava de estudar e não queria abrir mão de minhas aspirações... tomei conhecimento do prenúncio de cegueira (...) decidi aprender o manejo da bengala e a ler e 
escrever por meio do sistema braile. $\mathrm{O}$ meu percurso profissional tal como o acadêmico é um incessante exercício de versatilidade... Troquei a máquina de datilografia pelo computador, utilizo leitores de tela com síntese de voz como meios de acesso à leitura, escrita e à informação em geral, o que possibilita acionar o correio eletrônico e navegar na internet de forma autônoma (...). (Sá, 2002, passim ).

Outro ponto que cabe retomar de Merleau-Ponty (1971) refere-se à importância da linguagem dentre os objetos culturais: na experiência do diálogo, quando se parte da experiência perceptiva, em que se fala da imersão do sujeito no mundo, a ação surge sempre como um movimento significativo e intencional num campo de articulação de sentidos. Cada um libera e amplia os significados do outro, trazendo nova dimensão ao que é percebido do mundo. A ênfase na importância cultural da linguagem leva a perguntar como ocorre o diálogo com a pessoa surda. Sobre essa questão serão retomados alguns dados do dia-a-dia daquele que não dispõe do sentido da audição. Como ilustra Fonseca, psicanalista que atende deficientes auditivos, o bebê, desde a gestação está em situação diferente daqueles que ouvem, como se pode ler a seguir:

1. o bebê não teve oportunidade de registrar os sons ( principalmente a voz da mãe) em seu ambiente intra-uterino (...)

2. o bebê não pode ouvir sua própria voz, apesar de perceber que faz esforços

para a emissão (...)

3. o bebê não recebe o banho sonoro da fala dos pais (...)

4. a comunicação entre pais ouvintes e uma criança cuja deficiência auditiva ainda não foi diagnosticada é altamente apoiada em elementos sonoros(...)

5. ouvir a voz da mãe é um meio de estar certo de sua presença, apesar de não estar próxima fisicamente(...)

6. estando mais sujeito a quebras de continuidade da presença materna... conseqüências podem ocorrer (...) (Fonseca, 2001, p.43-44).

Essas afirmações reiteram que a experiência perceptiva da criança surda, ou com deficiência auditiva, resulta de uma organização dos dados provenientes do senso tátil, cinestésico, visual e olfativo. Sem a audição, como poderia ocorrer o diálogo com essa criança? Retomando a afirmação de Merleau-Ponty (1971, p. 143) "O sujeito penetra no objeto pela percepção e através de seu corpo o objeto regula diretamente seus sentimentos..." , pode-se afirmar que o ponto de partida para o diálogo com essa criança é a atenção ao que ela manifesta: gestos, expressões e atitudes do seu corpo no mundo onde está imersa. Cada órgão dos sentidos interroga o objeto à sua maneira. A criança surda dirige e passeia o olhar para saber sobre as pessoas e objetos que a rodeiam de modo diferente da criança que dispõe da visão e também da audição. A visão nada seria para a criança surda, se não fosse um certo uso que ela faz do olhar. O seu estilo de fixar, contemplar, perscrutar, comparar vai revelando novos aspectos dos objetos e do seu próprio corpo, ao encontrar diferentes maneiras de explorá-los, compondo sua experiência perceptiva.

A atenção às suas manifestações por parte dos pais ou de outro cuidador poderá indicar suas formas de participação, ou de ausências de participação, que revelam suas vias de percepção e suas experiências perceptivas. Essa atitude, propícia à experiência do diálogo, evidencia disposição para a busca dos meios apropriados para que a comunicação com a criança possa ter seu ponto de partida..

O que está sendo enfatizado, sempre, é a importância do contato, no mundo que este ser precisa ter, com pessoas e objetos, por meio dos sentidos de que dispõe, sempre em interação e nunca separado, apenas como um espectador. Essa atitude MerleauPonty denomina freqüentação ingênua do mundo, que ocorre quando uma percepção guarda todas as relevâncias corporais, pois, como afirma esse filósofo, "meu corpo é a textura comum de todos os objetos e ele é, pelo menos em relação ao mundo percebido o instrumento geral de minha compreensão" (Merleau-Ponty, 1971, p. 224).

Em vários momentos de sua obra o filósofo reitera, também, que é a freqüentação ingênua do mundo que torna possível a reflexão, pois o mundo está aí antes de qualquer análise:

só me foi dado chamar o mundo e os outros a mim e tomar conhecimento da reflexão, porque desde o início estava fora de mim, junto aos outros, sendo que a todo momento essa experiência vem alimentar miha reflexão (Merleau-Ponty, 1971, p. 56).

É pois, da reflexão sobre o vivido e da atenção à experiência perceptiva que emergem os significados da pessoa no mundo. Assim, por exemplo, a reflexão da criança com deficiência visual surge da sua experiência de habitar o mundo por meio de sua apalpação tátil, em que interroga o objeto de forma mais próxima do que se o fizesse com o olhar. A 
velocidade e a direção de suas mãos é que a farão sentir as texturas do liso e do rugoso, a temperatura fria ou quente, o ar mais abafado quando se aproxima de uma parede, acompanhado pela alteração de sua voz ouvida e sua voz articulada, que se altera frente a um obstáculo ou em ambiente aberto. Essas percepções de tatear, que ocorrem com seus movimentos de mãos e dedos, de articular a voz, de ouvir, de sua comunicação e de sua locomoção no espaço estão unidas no seu corpo, no mundo, e compreendidas pela reflexão sobre cada uma dessas experiências.

Merleau-Ponty mostra que essa unidade de reflexão não é soma ou resultado, mas que é preciso sentir de alguma maneira para poder pensar, e que todo o pensamento advém de uma carne. Assim, para poder saber da criança com deficiência sensorial visual, auditiva, ou surdocegueira - é necessário aproximar-se de seu corpo e da experiência que ela tem através dos sentidos de que dispõe, de maneira total e não fragmentada. $\mathrm{O}$ corpo próprio de cada um está no mundo - o surdo olha todas as coisas e também pode olhar a si mesmo, toca as coisas e toca-se tateante; da mesma forma, o cego ouve o que o cerca e se ouve também, é sensível à temperatura e vibrações do que o cerca e de si mesmo - tem suas experiências Sintetizando, o que ficou dito, e retomando o título desta comunicação pode-se afirmar: A Experiência Perceptiva é o Solo do Conhecimento.

\section{REFERÊNCIAS}

Fonseca, V.R.J.B.M. (2001) Desenvolvimento psicológico na deficiência auditiva. Em Fonseca, V.R.J.B.M (Org.), Surdez e Deficiência Auditiva: a trajetória da infância a idade adulta.(pp. 39-57) São Paulo: Casa do Psicólogo.

Keller, H. (1939) A história de minha vida.( J. E. Veiga, Trad.) Rio de Janeiro: José Olympio. (Originalmente publicado em inglês s/d.)

Masini, E.F.S. (1994) $O$ perceber $e$ o relacionar-se do deficiente visual: orientando professores especializados. Brasília: CORDE.
Merleau-Ponty, M. (1971) Fenomenologia da percepção. (R. di Piero, Trad.) São Paulo: Freitas Bastos (Originalmente publicado em francês em 1945).

Merleau-Ponty, M. (1975) O olho e o espírito (Coleção Pensadores,Textos Escolhido XLI) (P. Moraes Filho, Trad.) São Paulo: Abril Cultural. (Originalmente publicado em francês em 1960).

Moura, M. C.; Lodi A.C. e Pereira, M.C. (Org.) (1993) Língua de sinais e educação do surdo. (Série de Neuropsicologia, V. 3) São Paulo: Tec Art.

Ochaita, E. (1984) Una aplicación de la teoria piagetiana al estudio del conocimiento espacial en los niños ciegos .Revista Infancia y Aprendizage, 25 , 81-104.

Ormelezi, E. (2000) Os caminhos da aquisição do conhecimento e a cegueira: do universo do corpo ao universo simbólico. Dissertação de Mestrado, Universidade de São Paulo, São Paulo.

Rodrigues, N. (1993) Organização neural da Linguagem. Em Moura, M. C.; Lodi A.C.e Pereira, (Org.), M.C: língua de sinais e educação do surdo. (Série de Neuropsicologia, V. 3) (pp. 5-18) São Paulo: Tec Art.

Sá, E. (2002) A bengala e a mulher invisível. Em Masini, E.F.S. Do sentido...pelos sentidos...para o sentido: sentidos das pessoas com deficiências sensoriais. (pp.27-32) Niterói/ São Paulo: Intertexto/Vetor.

Salomon, S. M. (2000) Deficiente visual - um novo sentido de vida: proposta psicopedagógica para ampliação da visão reduzida. São Paulo: LTr.

Sacks, 0.(1997) Ver e não ver . Em Um antropólogo em Marte . (pp.123-164) São Paulo: Companhia das Letras.

Spinelli, M. (2002)O médico, o deficiente auditivo e sua família. Em Masini, E.F.S, Do sentido...pelos sentidos...para o sentido: sentidos das pessoas com deficiências sensoriais. (pp. 209-216) Niterói/ São Paulo: Intertexto/Vetor.

Veitzman, S. (2002) O oftalmologista frente à pessoa deficiente visual e a família. Em Masini, E.F.S.(Org.), Do sentido... pelos sentidos... para o sentido: sentidos das pessoas com deficiências sensoriais. (pp.217-220) Niterói/ São Paulo: Intertexto/Vetor.

Recebido em 18/02/2003

Revisado em 26/05/2003

Aceito em 30/05/2003 